\title{
Mucopolysaccharide Storage Disease in Three Families of Cats with Arylsulfatase B Deficiency: Leukocyte Studies and Carrier Identification
}

\author{
MARK E. HASKINS ${ }^{58}$, PETER F. JEZYK, AND DONALD F. PATTERSON \\ Sections of Pathology and Medical Genetics, University of Pennsylvania School of Veterinary Medicine and the \\ University of Pennsylvania Genetics Center, Philadelphia, Pennsylvania, USA
}

\begin{abstract}
Summary
This report gives a more complete description of pathologic and enzymologic findings in the feline Maroteaux-Lamy Syndrome based on additional studies in the cat originally described, three other affected Siamese cats from two additional families and an affected kitten produced by an experimental mating between obligate heterozygotes from two independently ascertained families.

All affected animals had facial dysmorphia with a small head and broad, shortened maxilla. None had hepatosplenomegaly. All had a diffuse ground glass appearance of all layers of the cornea.

All long bones had multiple severe exostoses with epiphyseal dysplasia and irregular articular surfaces.

There was no indication in these cats of any deficit comparable to what is defined in man as mental retardation.

The electrophoretic patterns obtained showed that the primary glycosaminoglycan (GAG) excreted in the urine by the affected cats was dermatan sulfate.

In two human mucopolysaccharidoses (MPS) VI patients and all five affected cats, $90-100 \%$ of the circulating polymorphonuclear (PMN) leukocytes contained, by light microscopy, excessive coarse granulations in the cytoplasm. In the human MPS VI patients, most PMN leukocytes contained, by electron microscopy, small (0.2-0.5u) round membrane bound inclusions, a majority of which contained an amorphous to granular electron dense material. The predominant inclusion type in the cat varied among families: lamellar, granular, and crystalloid, but all three inclusion types were present in some cells of all affected individuals.

The data indicate that the detection of normals, heterozygotes, and homozygotes for the mutant gene was possible using an assay for arylsulfatase B (ASB) in peripheral blood leukocytes. The existence of an obligate heterozygote which has very low ASB activity with the nitrocatechol sulfate assay indicates that clinical criteria must be combined with assays of enzyme activity before an individual can be defined as affected.

Pedigree information in the three independently ascertained families of cats is consistent with autosomal recessive inheritance. An experimental mating between obligate heterozygotes in families 2 and 3 produced a kitten with characteristic signs and enzymatic deficiency of the syndrome, indicating that the same locus, and in all probability the same mutant allele, is involved in these two families.
\end{abstract}

\section{Speculation}

This feline model of mucopolysaccharidosis VI (MaroteauxLamy Syndrome) can be produced by experimental mating and should allow advances in the understanding of the pathogenesis and approaches to therapy for this and related genetic storage diseases.
In man, the genetic MPS are a group of well-recognized syndromes resulting from defects in GAG degradation, each syndrome having a characteristic combination of clinical signs, urinary GAG excretion, and a specific lysosomal enzyme deficiency $(10,27,31,34,40,41,46)$.

Human MPS VI, first described in 1963, is characterized by growth retardation, facial abnormalities that include apparent hypertelorism, a depressed bridge of the nose, full cheeks, and relatively broad jaws; corneal opacity, hepatosplenomegaly, normal or near normal intelligence, and dysostosis multiplex $(24,27$, 41). Alder-Reilly bodies are prominent in peripheral granulocytic leukocytes $(16,41)$. The urinary GAG's are considerably elevated, and the predominant urinary GAG is dermatan sulfate $(33,34$, 44). The enzyme defect was initially identified as ASB that was subsequently shown to be an $\mathrm{N}$-acetylgalactosamine-6-sulfate sulfatase, an activity required for complete degradation of chondroitin-4-sulfate and dermatan sulfate $(1,6,13,15,26,32,38,42,43)$.

The first authentic animal model of a MPS was reported by us in a single Siamese cat with a syndrome resembling MPS VI (Maroteaux-Lamy Syndrome) $(9,18)$. This report gives a more complete description of pathologic and enzymologic findings in the feline Maroteaux-Lamy Syndrome based on additional studies in the cat originally described, three other affected Siamese cats from two additional families, and an affected kitten produced by an experimental mating between obligate heterozygotes from two independently ascertained families. Observations on inclusion bodies in PMN leukocytes in the cats are compared with those in two human patients with MPS VI.

\section{MATERIALS AND METHODS}

Five affected animals, four siblings, and four obligate heterozygotes were studied (Fig. 1): the propositus in family 1, the subject of the initial clinical and biochemical descriptions of this syndrome in the cat $(9,18)$, and her mother; two affected individuals, a male and a female from family 2 , their male sibling, and both their parents; the single affected cat in family 3 and her father; the single cat and three siblings produced from a mating between the female obligate heterozygote from family 2 and the male obligate heterozygote from family 3 . Blood from 13 normal cats (including two Siamese), blood and urine from a $23-y$-old male human MPS VI patient (C.R.) (55) and blood from an 8-yrold female human MPS VI patient (J.T.) (56) were also studied.

Ascertainment of the affected animals in families 1 and 3 was by referral from veterinary practitioners in private practice to the Veterinary Hospital, University of Pennsylvania. These animals were presented for study without a diagnosis. The animals in family 2 were ascertained by a practitioner subsequent to the publication of the syndrome in the clinical veterinary literature (9). All of these cases were identified within an 18-month period. 
FAMILY I

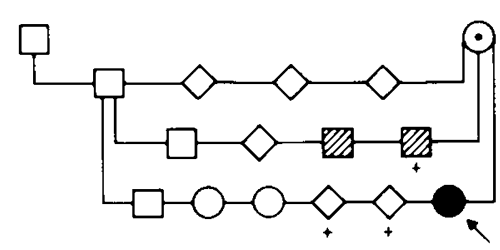

FAMILY 2

FAMILY 3

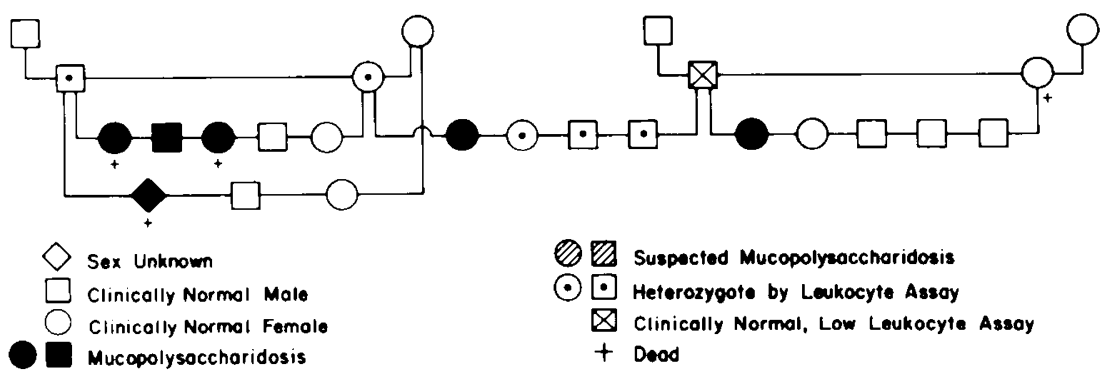

Fig. 1. The pedigrees of three families of Siamese cats with members affected with MPS VI. The individuals studied are the products of a motherson mating in family 1 , brother-sister matings in families 2 and 3, and a mating arranged between obligate heterozygotes from families 2 and 3.

URINE

Urine from the cats and a human MPS VI patient (C.R.) was analyzed. Spot tests for GAG (7) were performed on fresh urine. Electrophoresis of cetylpyridinium chloride precipitated urine was carried out by the method of Wessler (52) on cellulose acetate strips (53) for $4 \mathrm{hr}$ at 100 volts. After electrophoresis, the strips were stained with $0.1 \%$ toluidine blue in water and washed with a mixture of methanol and acetic acid $\left(200 \mathrm{H}_{2} \mathrm{O}: 2\right.$ methanol:0.1 acetic acid).

\section{PERIPHERAL LEUKOCYTES}

Blood samples from the cats and human patients were taken in EDTA for light microscopy or heparin for electron microscopy and enzyme determinations.

Leukocyte separation using heparinized blood is a modification of that of Skoog and Beck (39). One part of blood was mixed with one part of 3\% dextran MW 170,000 (54) and the erythrocytes were allowed to settle for $30 \mathrm{~min}$. The leukocyte-rich supernatant was centrifuged. If the cells were to be used for enzyme determinations the resulting pellet was washed with $0.2 \% \mathrm{NaCl}$, recentrifuged, again washed with $0.2 \% \mathrm{NaCl}$, centrifuged, and the cells frozen at $-70^{\circ} \mathrm{C}$ until assayed. The cells for electron microscopy were placed in $2 \frac{1}{2} \%$ gluteraldehyde in $0.2 \mathrm{M}$ cacodylate buffer with $0.1 \mathrm{M} \mathrm{CaCl}_{2}$ for $30-90 \mathrm{~min}$. The cells were then recentrifuged and suspended in cold $0.85 \% \mathrm{NaCl}$ (with $10 \%$ sucrose) until they were embedded. A pellet of cells was established in the tip of a small plastic capsule by centrifugation and embedded in Spurr, sectioned on a Sorvall MT2-B microtome to 700 angstroms, stained with lead citrate-uranyl acetate, and examined using a Zeiss EM9S-2 electron microscope.

\section{ENZYME ASSAYS}

ASB (EC.3.1.6.1) activity of leukocytes was determined by the method of Beratis et al. (6), incubating 150 ul of cell lysate (50$500 \mathrm{ug}$ of protein) with $600 \mathrm{ul}$ of $0.0625 \mathrm{M}$ p-nitrocatechol sulfate (54) in $0.5 \mathrm{M}$ acetate buffer with $10^{-2} \mathrm{M}$ barium acetate. The buffer $\mathrm{pH}$ was 5.8. The final $\mathrm{pH}$ was 6.3 after addition of the substrate. The reaction was incubated at $41^{\circ} \mathrm{C}$ and after 30 and 90 min, 375 ul of digest was added to $375 \mathrm{ul}$ of $1 \mathrm{~N} \mathrm{NaOH}$. The resultant mixtures were centrifuged and then read at $515 \mathrm{mu}$ (Beckman DU 2400 spectrophotometer). All assays were in duplicate, as was a blank using deionized water in place of cell extract. The protein of Lowry et al. (23) was determined, in duplicate, on
$25 \mathrm{ul}$ of cell extract. A regression coefficient $\left(8.484 \times 10^{-5} \mathrm{mM} /\right.$ O.D.) was calculated using dilutions of P-nitro-catechol (54) in 1 $\mathrm{N} \mathrm{NaOH}$. The specific activity is expressed as the nanomoles of P-nitro-catechol released per hour (between 30-90 min) per $\mathrm{mg}$ of cell protein.

\section{RESULTS}

\section{CLINICAL FEATURES}

The youngest animal was seen at 9 wk of age (the product of the cross between families 2 and 3 ) and was clearly affected at that age. Reports by owners of the affected individuals indicate the phenotype may be apparent as early as 3-6 wk postpartum. The oldest animals are now $4 \frac{1}{2}$ yr of age (family 1 and 3 ). Figure 2a illustrates a normal Siamese facies. All affected animals had facial dysmorphia (Figure 2b, c) with a small head and broad, shortened maxilla. The upper eyelids appeared swollen and the palpebral fissures were somewhat narrow. The animals had a crouched posture with abducted stifles (knees), cervical rigidity, and awkward gait. Three of the five animals, one in each family, had pectus excavatum. None had hepatosplenomegaly. All had a diffuse ground glass appearance of all layers of the cornea with a prominent Descemet's membrane. Retinal atrophy was present in family 1 ; corneal vascularization occurred in family 2 as did pupils that only react to very bright light, which may indicate otherwise inapparent retinal disease.

The radiographic osseous change (Fig. 3) was most severe in the two oldest cats (families 1 and 3 ). In those animals, the spine was severely affected with fusions and multiple proliferative lesions in the cervical, thoracic, and lumbar regions. The odontoid process was normal. The pelvis had shallow irregular acetabulae. The femoral heads were flattened and bilaterally subluxated with a valgus deformity of the femoral neck. All long bones had multiple severe exostoses with epiphyseal dysplasia and irregular articular surfaces. The short tubular bones were similarly affected.

The ribs were broad at the costocartilage junction, the costocartilage was excessively convex and the caudal sternebra concave. The spondyloepiphyseal dysplasia was progressive over the $2 \frac{1}{2} \mathrm{yr}$ the older animals have been studied. The affected animals in family 2 had cervical fusion and bilateral hip subluxation similar to the older animals, but the epiphyseal dysplasia of the long bones was less severe. The affected animal from the cross between families 2 and 3 had, at 15 wk of age, irregularly calcified and hypoplastic epiphyses most evident in the proximal humeri, prox- 

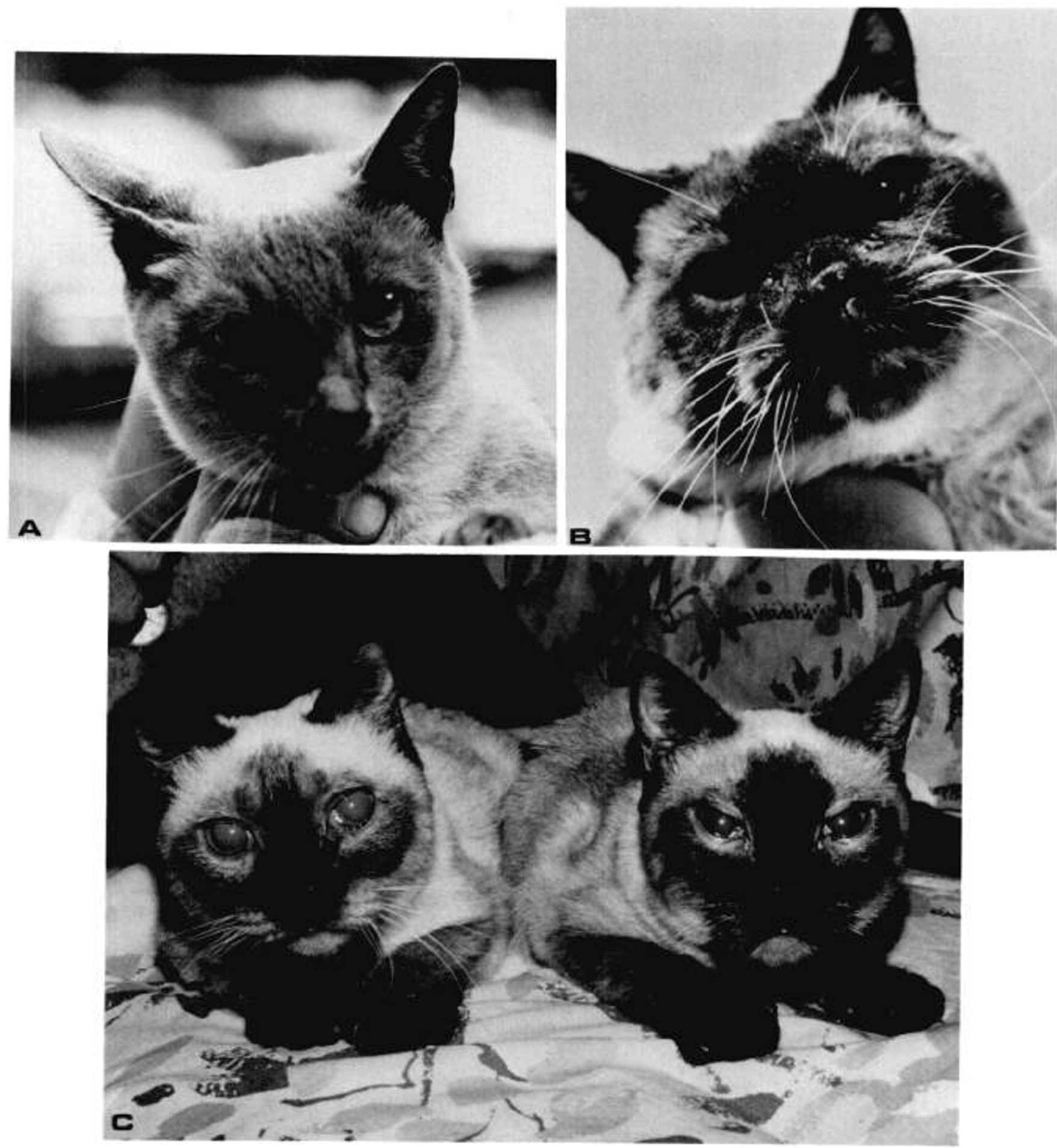

Fig. 2. $a$ The facies of a normal female Siamese cat at 3 yr of age. $b$ The affected cat from family 3 at 3 yr of age. Note the depressed bridge of the nose, apparent hypertelorism, broad maxilla, and flattened facies. $c$ The affected brother and sister from family 2 at 6 months of age. Note the flattened facies, corneal clouding, and large fore paws.

imal femori, and cervical spine. The odontoid process was markedly hypoplastic.

Mentation is difficult to assess in animals. There was, however, no indication in these cats of any deficit comparable to what is defined in man as mental retardation. All of the affected cats were alert and responsive, affectionate, and exhibit the full range of behavioral characteristics seen in normal cats of similar age, although superimposed on severe skeletal disease which limits joint mobility.
URINE

Spot tests on urine from all clinically affected animals and C.R., the human patient, were positive. Urine from all the clinically normal animals, including obligate heterozygotes, were negative for GAG by the spot test.

The electrophoretic patterns obtained showed that the primary GAG excreted by the affected cats in families 2 and 3 comigrated with that of one human MPS VI patient (C.R.) as well as that of 

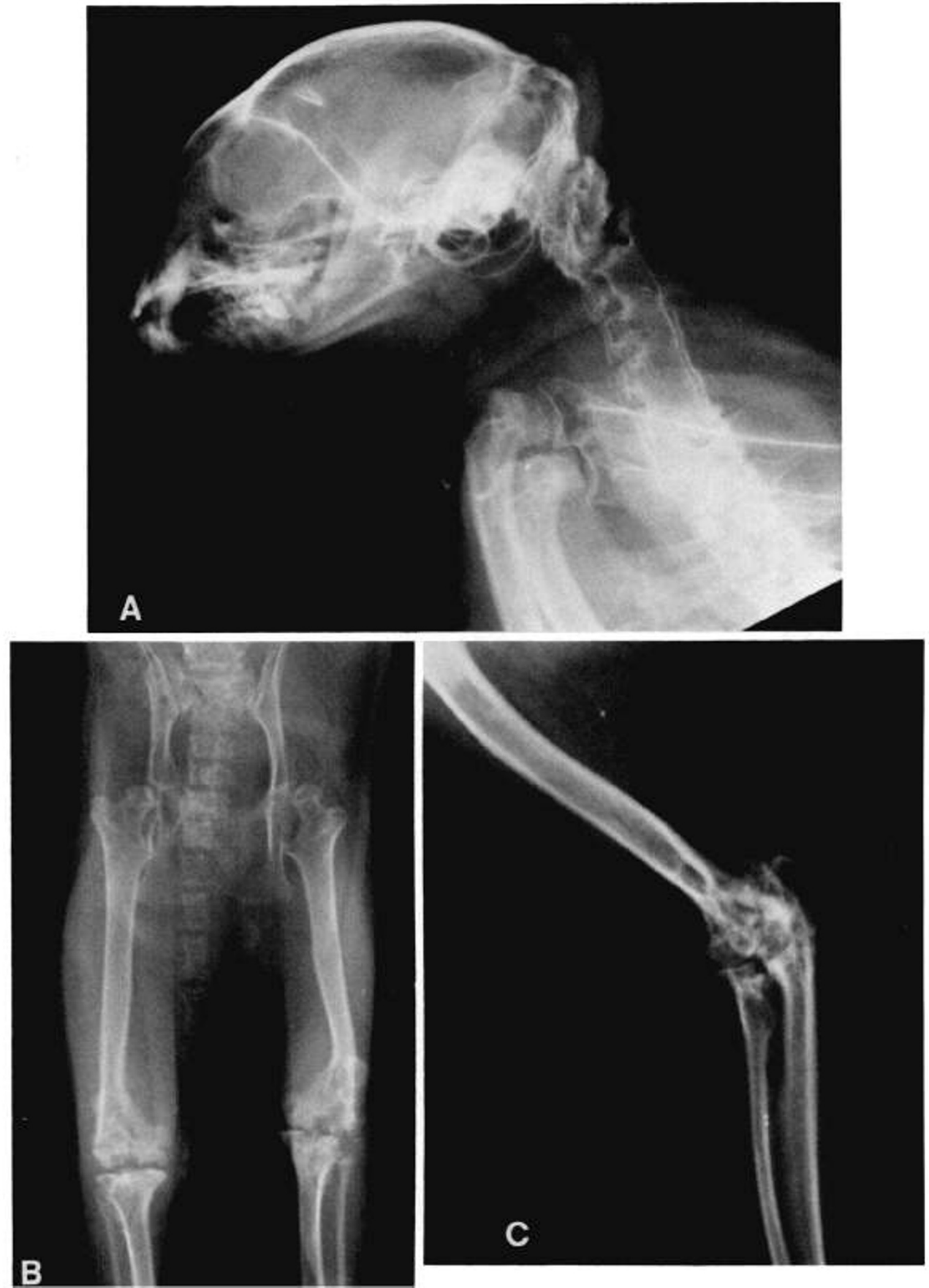

Fig. 3. Radiographs of the affected cat of family 1. $a$ Lateral radiograph of the head and cervical vertebrae. Vertebrae C2-6 appear fused. Note the ribs that are broad at the costocartilage junction. $b$ Ventrodorsal radiograph of the pelvis and stifles. Note the bilateral hip subluxations and pronounced epiphyseal dysplasia of the stifle (knee). $c$ Lateral radiograph of the elbow. Note the irregular osseous proliferation at the ends of the long bones and the loss of a smooth articular surface. 
the cat in family 1, which had previously been shown to be dermatan sulfate (18). A small amount of chondroitin sulfate and a trace of heparan sulfate were also present in the affected cat's urine. Normal cat urine contained primarily chondroitin sulfate with a small amount of dermatan sulfate and a trace of heparan sulfate.

\section{PERIPHERAL LEUKOCYTES}

Light Microscopy. The human MPS VI patients had abnormal granules in the cytoplasm of $90-100 \%$ of peripheral granulocytic leukocytes and $1-5 \%$ of lymphocytes using Wright-Geimsa stain. These granules stained metachromatically with toluidine blue (48). In all five affected cats, $90-100 \%$ of the PMN leukocytes contained excessive coarse granulations in the cytoplasm, using Wright-Geimsa stain, which also stained metachromatically with toluidine blue. Abnormal granulations in lymphocytes were not recognized.

\section{ELECTRON MICROSCOPY}

Neutrophils and eosinophils from the normal cat contained organelles consistent with those seen in normal human cells.

Most circulating PMN leukocytes from the affected cat in family 1 contained, in section, 20-30 round to oval membrane bound lamellar inclusions from $0.5-1.0 \mathrm{u}$ in diameter (Fig. 4a). Within the same animal, cells were found with large granular inclusions.

In most PMN leukocytes from the affected cats in family 2 , the inclusions were small (0.1-0.3 u), numerous (on the order of 50 per section), and contained granular material (Fig. 4b). However, there is a population of cells with inclusions similar in size and number to the cat from family 1 , some contained granular material (Fig. 4c) and some which contained granular material, lamellae, and crystalloid bodies.

The majority of PMN leukocytes from the affected cat of family 3 contained, in section, 30-50 large membrane found inclusions $(0.3-1.0 \mathrm{u})$ which had prominent crystalloid bodies as well as granular and lamellar structures (Fig. 4d). These were present both in the peripheral blood and bone marrow.

In the affected animal that was the product of a mating between obligate heterozygotes from families 2 and 3 , the inclusions were granular as seen in family 2 .

The predominant inclusion type in the cat, therefore, varied among families: lamellar (family 1), granular (family 2 and the cross between families 2 and 3 ), and crystalloid (family 3 ), but all three inclusion types were present in some cells of all affected individuals.

In the human MPS VI patients, most PMN leukocytes, in section, contained on the order of 50-100 small $(0.2-0.5 \mathrm{u})$ round membrane bound inclusions, a majority of which contained an amorphous to granular electron dense material (Fig. 4e, f) although some cells contained fewer large inclusions. Many mononuclear cells also contained similar inclusions, only fewer in number (generally less than 10 ) per cell. Lamellar material was present in 1-5\% of PMN leukocytes from one human patient (J.T.) (Fig. 4e). Lamellae were more common in those mononuclear cells containing abnormal inclusions.

The granular inclusions seen in cells from affected cats were consistent with those found in the human MPS VI patients examined here, and with those reported in lymphocytes of patients with MPS IH, II, III, and V $(3,28)$ and are assumed to represent stored GAG (47). Lamellar inclusions, however, are more typically associated with lipids as seen in Tay-Sach's disease $(36,37,45)$. Topping et al. (47) has reviewed evidence that lamellar structures contain glycolipid. An explanation for the presence of glycolipid can be made from observations that GAG accumulation products inhibit enzymes involved in ganglioside degradation and result in glycolipid and ganglioside accumulation as secondary consequences of the primary enzyme defect $(2,20)$. Lamellar inclusions have been reported to occur infrequently in the other MPS in man-in central nervous system neurons (most often observed), keratyocytes, retinal ganglion cells, eccrine glands, dermal, scleral, and choroidal fibroblasts, liver, lymphocytes, and renal capsular epithelium $(4,5,9,17,21,28,29,35,46,47)$. There are few reports of the ultrastructural abnormalities in MPS VI. Kenyon et al. (19) showed granular and lamellar inclusions in cells of the cornea and sclera. Tondeur and Neufeld (46) report small inclusions with granular material and lipid-like spherules in liver from a MPS VI patient. The other studies of MPS VI ultrastructure have shown only granular or empty inclusions in endothelial cells and fibroblasts $(49,50)$.

\section{ENZYMOLOGY}

Table 1 lists the activities of ASB in peripheral leukocytes obtained from 13 normal cats, 4 obligate heterozygotes for MPS VI, 5 homozygotes for MPS VI, 4 potential heterozygotes for the disease in the cat, and 2 human MPS VI patients.

In 14 of 72 incubations of the 13 normal cats studied, the enzyme activity was below the mean $\pm 1 \mathrm{SD}$ of the heterozygote values. The mean for only one normal individual, however, fell below this value. This animal had a mean ASB activity of 35.5 \pm 0.7 (three incubations of one blood sample) and was a clinically normal Siamese cat which was a patient at a local veterinary hospital. It has not been possible to determine whether this animal is truly normal or is, in fact, a heterozygote. The frequency of this allele has not been determined in the Siamese cat population and, therefore, a probability cannot be assigned to the chance of finding a carrier by a random screening method. It is of note, however, that three families of Siamese cats with the disease have been recognized within only an 18 -month period and within 100 miles of each other. This would indicate the allele is not extremely rare.

The enzyme activity of the obligate heterozygote father in family 3 was consistently in the affected range. He was a clinically normal adult cat (over 3 yr of age) without radiographic abnormality, corneal clouding, coarse leukocyte granulations, or excessive GAG excretion in his urine. Similar findings, where apparently normal obligate heterozygotes have very low enzyme activities, have been described in man in families with metachromatic leukodystrophy $(12,14,22)$ and Tay-Sach's disease $(11,30,51)$. Breeding experiments are being conducted and a natural substrate is being developed to further investigate this individual.

The data indicate that detection of normals, heterozygotes, and homozygotes for the mutant gene is possible using an assay for ASB in peripheral blood leukocytes. The variability of the normal and heterozygote values for any individual, however, necessitates multiple samples in order to assign an individual to either class, as in human MPS VI (6). The existence of an obligate heterozygote that has very low ASB activity with the nitrocatechol sulfate assay indicates that clinical criteria must be combined with assays of enzyme activity before an individual can be defined as affected.

\section{GENETICS}

Pedigree information in the three independently ascertained families of cats (Fig. 1) is consistent with autosomal recessive inheritance: naturally occurring cases were the result of consanguineous matings, females as well as males are affected, and multiple cases appear in a single sibship. In addition, all parents tested were clinically normal but had levels of ASB which were consistent with that expected for an obligate heterozygote (approximately $50 \%$ of the normal level) except for the father in family 3 whose ASB was lower than expected as discussed above. All families with affected members are of Siamese ancestry and are, therefore, probably related. However, extended pedigree information is not available, and common ancestors cannot be identified. An experimental mating between obligate heterozygotes in families 2 and 3 produced a kitten with characteristic signs and enzymatic deficiency of the syndrome, indicating that the same locus, and in all probability the same mutant allele, is involved in these 2 families. 

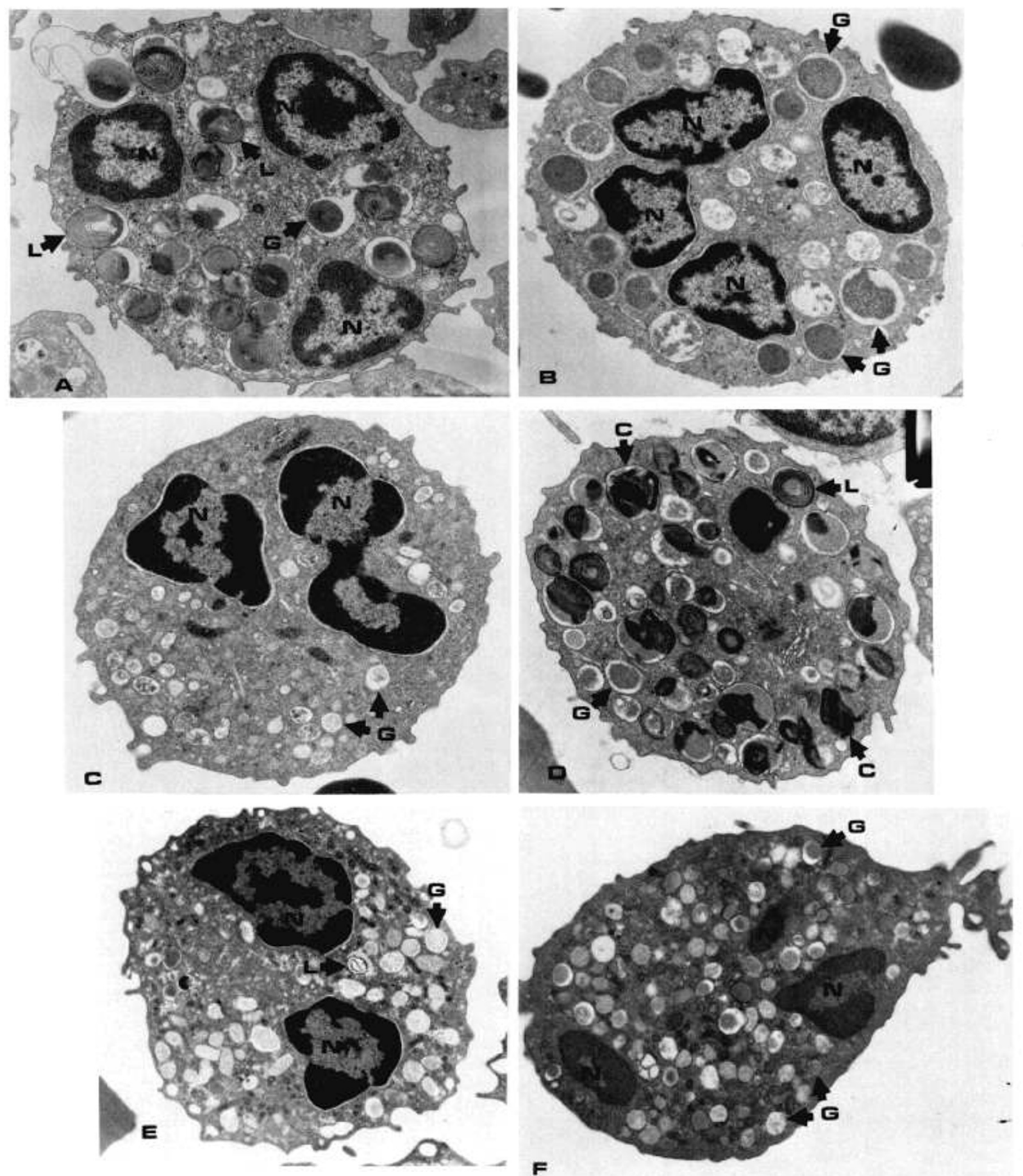

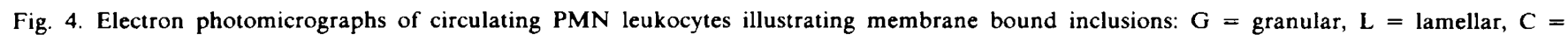
crystalloid, $\mathrm{N}=$ nucleus. $a$ From the affected cat of family $1, \mathrm{X} 6500 . b$ From the affected female cat of family $2, \mathrm{X} 6800$. $c$ From the affected male cat of family $2, \mathrm{X} 6000$. $d$ From the affected cat of family 3, X 6500. $e$ From J.T., a human 8-yr-old female MPS VI patient, X 7000. $f$ From C.R., a human 23-yr-old male MPS VI patient, X 6200. 
Table 1. ASB activity in peripheral leukocytes of 13 normal cats, 4 obligate heterozygotes, 5 homozygotes, and 4 potential heterozygotes for feline MPS VI, as well as 2 human MPS VI patients ${ }^{1}$

\begin{tabular}{|c|c|c|c|c|c|}
\hline Subject & $\begin{array}{c}\text { No. } \\
\text { studied }\end{array}$ & $\begin{array}{c}\text { No. of } \\
\text { incubations }\end{array}$ & Mean $^{2}$ & $\begin{array}{c}\text { Range of } \\
\text { mean values }\end{array}$ & $\begin{array}{l}\text { Range of } \\
\text { individual assays }\end{array}$ \\
\hline \multicolumn{6}{|l|}{ Feline } \\
\hline Normal & 13 & 72 & $129.0 \pm 56.7$ & $35.5-253.5$ & $34.5-308.0$ \\
\hline \multicolumn{6}{|l|}{ Obligate } \\
\hline Heterozygotes & 4 & 30 & $44.2 \pm 27.3$ & $5.8-67.0$ & $0.0-68.8$ \\
\hline Mother, family 1 & 1 & 8 & $60.0 \pm 6.0$ & & $52.3-68.8$ \\
\hline Mother, family 2 & 1 & 9 & $44.1 \pm 11.1$ & & $32.2-64.5$ \\
\hline Father, family 2 & 1 & 3 & $67.0 \pm 0.8$ & & $66.2-67.7$ \\
\hline Father, family 3 & 1 & 10 & $5.8 \pm 3.8$ & & $0.0-12.0$ \\
\hline Homozygotes & 5 & 24 & $8.1 \pm 2.7$ & $5.1-11.1$ & $0.0-24.1$ \\
\hline Family 1 , female & 1 & 4 & $11.1 \pm 9.6$ & & $3.4-24.1$ \\
\hline Family 2 , female & 1 & 7 & $10.4 \pm 6.2$ & & $1.4-15.9$ \\
\hline male & 1 & 3 & $5.6 \pm 6.6$ & & $0.0-13.0$ \\
\hline Family 3, female & 1 & 4 & $8.2 \pm 4.0$ & & $5.4-14.1$ \\
\hline \multicolumn{6}{|l|}{ Family $2 \times$ Family 3} \\
\hline female & 1 & 6 & $5.1 \pm 3.4$ & & $2.2-9.4$ \\
\hline \multicolumn{6}{|l|}{ Potential } \\
\hline \multicolumn{6}{|l|}{ Heterozygotes } \\
\hline Family 2, male & 1 & 10 & $127.4 \pm 46.8$ & & $63.0-192.8$ \\
\hline \multicolumn{6}{|l|}{ Family $2 \times$ family 3} \\
\hline female & 1 & 8 & $58.2 \pm 20.2$ & & $30.7-88.1$ \\
\hline male & 1 & 8 & $49.1 \pm 11.4$ & & $31.8-66.1$ \\
\hline male & 1 & 8 & $56.1 \pm 6.1$ & & $49.2-65.1$ \\
\hline \multicolumn{6}{|l|}{ Human } \\
\hline Homozygotes & 2 & 4 & 7.4 & $1.6-13.2$ & $0.0-17.4$ \\
\hline C. R., male & 1 & 2 & 13.2 & & $9.1-17.4$ \\
\hline J. T., female & 1 & 2 & 1.6 & & $0.0-3.2$ \\
\hline
\end{tabular}

${ }^{1}$ Enzyme activity is expressed as nanomoles of 4-nitrocatechol per milligram of protein per hour.

${ }^{2}$ Mean $\pm \mathrm{SD}$.

\section{DISCUSSION}

The affected Siamese cats of this report are the first authentic animal models of a genetic MPS. They closely resemble the MPS VI syndrome in man in their clinical appearance, radiographic evidence of skeletal disease, corneal clouding, electron microscopic evidence of lysosomal storage in PMN leukocytes, and excretion of excessive urinary dermatan sulfate. Previously reported data (18) showing exaggerated accumulation of ${ }^{35} \mathrm{SO}_{4}$ incorporation into cultured fibroblasts from one affected cat and the deficiency of ASB in cultured fibroblasts suggested that the basic defect was the GAG degradation defect shown to be present in human MPS VI. The data on circulating leukocyte ASB in several affected and obligate heterozygote animals combined with an autosomal recessive mode of inheritance is further evidence that supports the congruency of this model to MPS VI in man and should allow its exploitation in pursuing an understanding of the pathogenesis of this disease and approaches to therapy.

\section{REFERENCES AND NOTES}

1. Austin. J. H.: Studies in metachromatic leukodystrophy. XII. Multiple sulfatase deficiency. Arch. Neurol., 28: 258 (1973).

2. Avila, J. L., Convit, J.: Inhibition of leucocytic lysosomal enzymes by glycosaminoglycans in vitro. Biochem. J., 152: 57 (1975).

3. Belcher, R.: Ultrastructure and cytochemistry of lymphocytes in the genetic mucopolysaccharidoses. Arch. Pathol., 93: 107 (1972)

4. Belcher, R.: Ultrastructure and function of eccrine glands in the mucopolysaccharidoses. Arch. Pathol., 96: 339 (1973).

5. Belcher. R.: Ultrastructure of the skin in the genetic mucopolysaccharidoses. Arch. Pathol., 94: 511 (1972).

6. Beratis, N. G., Turner, B. M., Weiss, R., and Hirschhorn, K.: Arylsulfatase B deficiency in Maroteaux-Lamy Syndrome: cellular studies and carrier identification. Pediatr. Res., 9: 475 (1975).

7. Berry, H. K., and Spinanger, J.: A paper spot test useful in study of Hurler's Syndrome. J. Lab. Clin. Med.. 55: 136 (1960).

8. Conrad, G., Sherman. D., and Dorfman, A.: An ultrastructural comparison of normal and Hurler Syndrome dermal fibroblasts. Pediatr. Res., 6: 563 (1972).
9. Cowell, K. R., Jezyk, P. F., Haskins, M. E., and Patterson, D. F.: Mucopolysaccharidosis in a cat. J. Am. Vet. Med. Assoc., 169:334 (1976).

10. Dorfman, A., and Matalon, R.: The mucopolysaccharidoses. In: J. B. Stanbury, J. B. Wyngaarden, D. S. Fredrickson: The Metabolic Basis of Inherited Disease. pp. 1218-1272 (McGraw Hill. New York, 1972).

11. Dreyfus, J.-C., Poenaru, L., and Svennerholm. L.: Absence of hexosaminidase A and $B$ in a normal adult. J. Med.. 292: 61 (1975).

12. Dubois, G., Haryer. K., and Baumann, N.: Very low arylsulfatase A and cerebroside sulfatase activities in leukocytes of healthy members metachromatic leukodystrophy family. Am. J. Hum. Genet., 29: 191 (1977).

13. Fluharty. A. L.. Stebens. R. L., Fung, D., Peak. S., and Kihara, H.: Uridine diphospho- $\mathrm{N}$-acetylgalactosamine-4-sulfate sulfohydrolase activity of human arylsulfatase B and its deficiency in the Maroteaux-Lamy Syndrome. Biochem. Biophys. Res. Commun., 64: 955 (1975).

14. Fluharty, A. L. Stebens, R. L., and Kihara, H.: Cerebroside sulfate hydrolysis by fibroblasts from a parent with metachromatic leukodystrophy. J. Pediatr., 92 782 (1978).

15. Fluharty, A. L., Stevens, R. L., Sanders, D. L., and Kihara, H.: Arylsulfatase B deficiency in Maroteaux-Lamy Syndrome cultured fibroblasts. Biochem. Biophys. Res. Commun., 59: 455 (1974).

16. Hansen, G.: Hematologic studies in mucopolysaccharidoses and mucolipidoses. Birth Defects Original Article Series. Vol. VIII, N. 3 pp 115-128 (1972).

17. Haust, M., Orizaga, M., Bryans, A., and Frank. H.: The fine structure of liver in children with Hurler's Syndrome. Exp. Mol. Pathol.. 10: 141 (1969).

18. Jezyk, P. F., Haskins, M. E., Patterson. D. F., Mellman, W. J., and Greenstein, M.: Mucopolysaccharidosis in a cat with arylsulfatase B deficiency: a model of Maroteaux-Lamy Syndrome. Science, 198: 834 (1977).

19. Kenyon, K. R.. Topping. T. M.. Green. W. R. and Maumenee, A. E.: Ocular pathology of the Maroteaux-Lamy Syndrome (systemic mucopolysaccharidosis type VI). Am. J. Ophthalmol., 73: 718 (1972).

20. Kint, J. A., Dacremont, G., Carton, D.. Orye. E., and Hooft. C.: Mucopolysaccharidosis: secondarily induced abnormal distribution of lysosomal isoenzymes Science, 181: 352 (1973).

21. Loeb, H., and Jonniaux, G.: Biochemical and ultrastructural studies in Hurler's Syndrome. J. Pediatr. 73: 860 (1968).

22. Loft, I. T., Dulaney, J. T., Milunsky, A., Hoefnagel, D., and Moser. H. W. Apparent biochemical homozygosity in two obligate heterozygotes for metachromatic leukodystrophy. J. Pediatr., 89: 438 (1976).

23. Lowry, O. H., Rosenbrough, N. J., Farr, A. L., and Randall, R. J.: Protein measurement with the folin phenol reagent. J Biol Chem 193.265 (1951)

24. Maroteaux, P., and Lamy, M.: Hurler's disease, Morquio's disease, and related mucopolysaccharidoses. J. Pediatr., 67: 312 (1965).

25. Maroteaux. P., Leveque, B., Marie. J., and Lamy, M.: Une nouvelle dyosostose 
avec elimination urinaire de chondroitine sulfate B. Presse Med., 71: 1849 (1963).

26. Matalon, R., Arbogast, B., and Dorfman, A.: Deficiency of chondroitin sulfate $\mathrm{N}$-acetylgalactosamine 4-sulfate sulfatase in Maroteaux-Lamy Syndrome. Biochem. Biophys. Res. Commun., 61: 1450 (1974).

27. McKusick, V.: Heritable Disorders of Connective Tissue. pp. 521-686 (C. V. Mosby, St. Louis, 1972).

28. Murata, $R$. Wohltman, $H$. Spicer $S$ S and Nagata, $T$. Fine structural and ultracytochemical studies on the lymphocytes in three types of genetic mucopolysaccharidoses. Virchows Archiv. (Cell Pathology), 25: 61 (1977).

29. Nagashima, K., Endo, H., Sakakibara, K., Konishi, Y., Miyachi, K., Wey, J. J., Seyuki, Y., and Onisawa, J.: Morphological and biochemical studies of a case of MPS II (Hunter's Syndrome). Acta. Pathol. Jpn.. 26: 115 (1976).

30. Navon, R., Padeh, B., and Adam, A.: Apparent deficiency of hexosaminidase A in healthy members of a family with Tay-Sach's Disease. Am. J. Hum. Genet. 25: 287 (1973)

31. Neufeld, E. F., and Fratantoni, J. C.: Inborn errors of mucopolysaccharide metabolism-faulty degradative mechanisms are implicated in this group of human diseases. Science, 169: 141 (1970).

32. O'Brien, J. F., Cantz, M., and Spranger, J.: Maroteaux-Lamy Disease (MPS VI), subtype A: deficiency of a N-acetylgalactosamine-4-sulfatase. Biochem. Biophys. Res. Commun., 60: 1170 (1974).

33. Pennock, C. A.: A review and selection of simple laboratory methods used for the study of glycosaminoglycan excretion and the diagnosis of the mucopolysaccharidoses. J. Clin. Pathol., 29: 111 (1976).

34. Pennock, C. A., and Barnes, I. C.: The mucopolysaccharidoses. J. Med. Genet., 13: 169 (1976)

35. Pouliquen, Y., Faure, J. P., Bissin, J., and Desvignes, P.: Ultrastructure de la cornee dans un cas de polydystrophie de Hurler. Arch Ophthalmol. (Paris) 27: 495 (1967)

36. Samuels, S., and Gonatas, N. K.: Formation of the membraneous cytoplasmic bodies of Tay-Sach's disease. Trans. Am. Neurol. Assoc., 88: 267 (1963)

37. Samuels, S., Korey, S. R., Gonatas, J., Terry, R. D and Weiss, M.: Studies in Tay-Sach's disease. IV. Membraneous cytoplasmic bodies. 1. Biochemistry 2. Ultrastructure. J. Neuropathol. Exp. Neurol., 22: 81 (1963).

38. Shapira. E., DeGregorie, R. R., Matalon, R., and Nadler, H. L.: Reduced arylsulfatase $B$ activity of the mutant enzyme protein in Maroteaux-Lamy Syndrome. Biochem. Biophys. Res. Commun., 62: 448 (1975)

39. Skoog. W. A., and Beck. W. S.: Studies on the fibrinogen, dextran and phytohemagglutinin methods of isolating leukocytes. Blood, 11: 436 (1956).

40. Spranger, J.: The systemic mucopolysaccharidoses. In: O. Frick, G. A. von Hamack, A. F. Muller, A. Prader, R. Schoen, H. P. Wolf: Ergebuisse der Inneren Medizen und Kinderheilkunde. pp. 165-265 (Springer-Verlag, New York, 1972).

41. Spranger, J., Koch, F., McKusick, V., Natzxchka, J., Wiedmann, H., and Zellweger, H.: Mucopolysaccharidosis VI (Maroteaux-Lamy Syndrome) Helv.
Paediatr. Acta, 25: 337 (1970)

42. Stumpf, D. A., and Austin, J. H.: Sulfatase B deficiency in the Maroteaux-Lamy Syndrome (MPS VI). Trans. Am. Neurol. Assoc., 97: 29 (1972).

43. Stumpf, D. A., Austin, J. H., Crocker, A. C., and LaFrance, M.: Mucopolysaccharidosis Type VI (Maroteaux-Lamy Syndrome) Am. J. Dis. Child., 126: 747 (1973).

44. Taniguchi, N., Koizumi, S., Masake, K., and Kobayashi, Y.: Diagnosis of genetic mucopolysaccharidosis: electrophoretic and enzymatic characterization of urinary glycosaminoglycans. Biochem. Med., 14: 241 (1975).

45. Terry, R. D., and Korey, S. R.: Studies in Tay-Sach's disease. V. The membrane of membraneous cytoplasmic body. J. Neuropathol. Exp. Neurol., 22: 98 (1963).

46. Tondeur, M., and Neufeld, E. F.: The mucopolysaccharidoses biochemistry and ultrastructure. In: R. A. Good, S. B. Day, J. J. Yunis: Molecular Pathology. Chapt. 25. pp. 600-621 (Charles C. Thomas, Springfield, Il, 1975).

47. Topping, T. M., Kenyon, K. R., Goldberg, M. F., and Maumenee, A. E. Ultrastructure ocular pathology of Hunter's Syndrome. Arch. Ophthalmol., 86. 164 (1971).

48. Undritiz, In: Sandez Atlas of Haematology. 2nd Edition. p. 36 (Sandez LTD, Basle, Switzerland, 1973).

49. Van Hoof, F.: Mucopolysaccharidoses. In: H. G. Hers, and F. Van Hoof Lysosomes and Storage Diseases. pp. 79-104 (Academic Press, New York, 1973).

50. Van Hoof. F., and Hers, H. G.: The mucopolysaccharidoses as lysosomal diseases In: B. Volk, S. M. Aronson: Sphingolipids, Sphingolipidoses and Allied Disorders. pp. 211-223 (Plenum Press, New York, 1972)

51. Vigdoff, J., Buist, N. R. M., and O'Brien, J. S.: Absence of $\alpha-\mathrm{N}$-acetyl-Dhexosaminidase A activity in a healthy woman. Am. J. Hum. Genet., 25: 372 (1973)

52. Wessler, E.: Analytical and preparative separation of acidic glycosaminoglycans by electrophoresis in barium acetate. Anal. Biochem., 26: 439 (1968).

53. Gelman Instrument Co. Ann Arbor, Michigan.

54. Sigma Chemical Co. St. Louis, Missouri.

55. Studied in cooperation with Dr. George Sack, Department of Medical Genetics, The Johns Hopkins Hospital, Baltimore, MD 21205 (USA)

56. Studied in cooperation with Dr. R. J. Desnick and Dr. J. Willner, Division of Medical Genetics, Mount Sinai School of Medicine, 5th Avenue and 100th Street. New York, NY 10029 (USA).

57. This research was supported by National Institutes of Health Genetics Cente grant GM 20138 and Public Health Service Training grant GM 00053 from the National Institute of General Medical Sciences.

58. Requests for reprints should be addressed to: M. Haskins, V. M. D., Ph. D. Sections of Pathology and Medical Genetics, School of Veterinary Medicine, University of Pennsylvania, Philadelphia, PA 19104 (USA)

59. Received for publication June 26, 1978.

60. Accepted for publication November 7, 1978. 